\title{
Contact Deformation of Alumina
}

\author{
Manjima Bhattacharya and Anoop Kumar Mukhopadhyay \\ Central Glass and Ceramic Research Institute, CSIR, 196 Raja S.C. Mullick Road, Kolkata 700032, India \\ Correspondence should be addressed to Anoop Kumar Mukhopadhyay, anoopmukherjee@cgcri.res.in
}

Received 28 September 2012; Accepted 15 October 2012

Academic Editors: K. L. Bing, H. I. Hsiang, C.-F. Yang, and K. Zupan

Copyright ( $) 2012$ M. Bhattacharya and A. K. Mukhopadhyay. This is an open access article distributed under the Creative Commons Attribution License, which permits unrestricted use, distribution, and reproduction in any medium, provided the original work is properly cited.

\begin{abstract}
The study of contact-induced deformations during hardness evaluation and the subsequent damage mechanisms of alumina under low loads deserves significant importance for its applications as wear-resistant inserts, biomedical implants, thin films, and armour plates, because the contact-induced brittle failure is an issue of major scientific concern that prevents their widespread commercial applications. However, the studies on hardness of dense, coarse grain alumina at ultralow load, for example, $1 \mathrm{~N}$, are still lacking. Therefore, the present study was conducted on a dense ( $\sim 95 \%$ of theoretical) coarse-grain $(\sim 20 \mu \mathrm{m})$ alumina at a low peak load of $1 \mathrm{~N}$ with varying loading rates $\left(10^{-3}-10^{0} \mathrm{~N} \cdot \mathrm{s}^{-1}\right)$ applied in depth sensitive indentation experiments. The results showed profuse presence of multiple micro-pop-in and pop-out events possibly linked to dislocation nucleations underneath the indenter. The critical resolved shear stress $\left(\tau_{\text {CRSS }}\right)$ was found to enhance with the increase in applied loading rates. The occurrences of the localized shear deformation band formation and microcracking in and around the indentation cavity were explained in terms of the correlation between the nanoscale plasticity events, the small magnitude of $\left(\tau_{\mathrm{CRSS}}\right)$, the maximum shear stress $\left(\tau_{\max }\right)$ developed just underneath the indenter, and the dislocation loop radius $\left(R_{d}\right)$.
\end{abstract}

\section{Introduction}

Alumina is well established as one of the most important structural and engineering ceramics. It has good oxidation resistance, chemical stability, good electric insulation, relatively high hardness, high wear resistance, and low friction in many contact situations. Therefore it is used as wearresistant inserts [1], biomedical implants [2], wear resist coatings [3], thin films [4], and armour plates [5]. All such high end engineering applications of alumina and/or its composites are basically controlled by contact-induced deformation mechanisms and damage initiation, as well as growth mechanisms at macro-, micro- and/or nanostructural length scale of the microstructure. This contactinduced brittle failure is an issue of major scientific and technical concerns which retards the rate of more widespread commercial applications of alumina ceramics. The most important surface mechanical property that defines the contact resistance of alumina is its hardness. Therefore, it is not surprising that hardness evaluation at various length scales consumes a significant amount of current research efforts in alumina [6-14]. Most of the commercially available alumina ceramics used for a variety of technical applications are coarse grained. They exhibit low to moderate hardness and, in addition, characteristically exhibit an R-curve behaviour which means that their crack growth resistance improves as the crack grows. In spite of the wealth of literature that exists on hardness of alumina measured at macro-, microscale [10-12], or nanoscale $[13,14]$ mostly for fine grain and/or submicrometer grain-sized alumina ceramics; however, the reports on hardness behaviour of dense coarse grained alumina ceramics are really rare [10]. It is important to recognize that depth sensitive indentation technique has emerged as a very effective technique to determine the surface mechanical properties of wide variety of materials [15-19].

Interestingly, alumina generally exhibits localized plastic deformation even under micronewton order of load [20]. The effect of these deformations are revealed by the occurrence of "multiple micro-pop-in" and "multiple micropop-out" events in the load-depth plots, followed by the formation of shear deformation bands and localized microcracking in and around the indentation cavity [21-37] and the formation of dislocation loops in the alumina sample. The 
detailed mechanisms of pop-in events which occur during indentation in ceramics are far from being well understood and may be strongly sensitive to the plane bearing the nanoindentation, nanoindenter tip radius, temperature and so forth, while the microscale hardness may [38-41] or may not be [42] sensitive to strain and loading rate variation.

Recently, significant effect of loading rate on hardness of glass [21-24] and alumina [25, 26, 43, 44] was reported. The occurrence of the pop-in behaviour was also reported for glass [21-24], polycrystalline alumina [25, 26, 43, 44], bulk metallic glass [27-29], sapphire [30], $\mathrm{GaN}$ [31], and $\mathrm{ZnO}$ [32]. The occurrence of pop-in has often been associated with shear localization [21-37]. There are though many contradictory viewpoints about their genesis in a wide variety of materials [37, 45-49], an unequivocal picture is yet to emerge. Therefore, the objective of the present work was to study in detail the effects of sharp contact, for example, a Berkovich indentation, induced deformation of a high density ( $\sim 95 \%$ of theoretical $)$ coarse grain $(\sim 20 \mu \mathrm{m})$ alumina with varying loading rates of $\left(10^{-3}-10^{0} \mathrm{~N} \cdot \mathrm{s}^{-1}\right)$ in the present indentation experiment at a very low peak load of $1 \mathrm{~N}$. The idea behind choosing the low peak load of $1 \mathrm{~N}$ was to be able to control the extent of damage that such a sharp contact event would create. The effects were explained in terms of shear localization, as well as the formation of dislocation loops under the indenter.

\section{Materials and Methods}

Since experimental details have been reported elsewhere [21$26,43,44]$, a brief description is mentioned here. Alumina discs of $\sim 10 \mathrm{~mm}$ in diameter and $\sim 3 \mathrm{~mm}$ in thickness were prepared by pressureless sintering in air at $1600^{\circ} \mathrm{C}$. Density of the sintered alumina discs was measured by Archimedes's principle. The polished alumina discs having surface roughness $\left(R_{a}\right)$ of $0.01 \mu \mathrm{m}$ were thermally etched for $1 \mathrm{~h}$ in air at a temperature of $1700^{\circ} \mathrm{C}$. Photomicrographs of the thermally etched alumina discs were taken by using a field emission scanning electron microscope (FE-SEM, Supra VP35, Carl Zeiss, Germany). These photomicrographs were used to measure the average grain size of the pressureless sintered alumina by using an image analyzer (Q500MC, Leica, UK).

A load controlled indentation technique was used with a commercial nanoindentation machine (Fischerscope H100XYp; Fischer, Switzerland) to evaluate hardness and Young's modulus of the alumina samples. A $5 \times 5$ array matrix was utilized for this purpose. Four random locations were chosen for experiments. The machine had depth sensing resolution of $1 \mathrm{~nm}$. The load sensing resolution of the machine was $0.2 \mu \mathrm{N}$. The indentation experiments were conducted with a Berkovich indenter attached to the machine. The indenter had a tip radius of $\sim 150 \mathrm{~nm}$ and a semiapex angle of $65.3^{\circ}$. The area function of the indenter tip was evaluated prior to each experiment. The dedicated software available in the control system of the machine corrected the experimentally obtained load $(P)$ versus depth of penetration $(h)$ data for tip blunting effect.

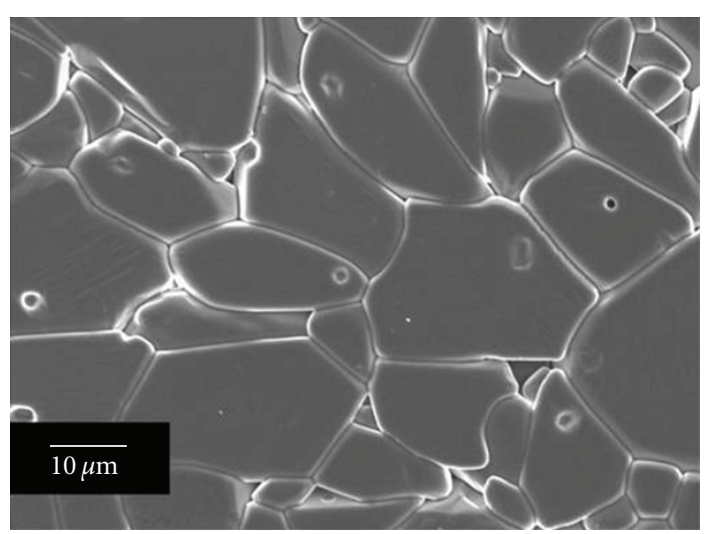

FIGURE 1: FE-SEM photomicrograph of the dense, coarse grained $(20 \mu \mathrm{m})$ alumina.

Following the DIN 50359-1 standard, the machine was finally calibrated with nanoindentation-based independent evaluation of hardness, $H(4.14 \mathrm{GPa})$ and Young's modulus, $E(84.6 \mathrm{GPa})$ values of a reference BK7 glass block (Schott, Germany). The standard reference glass block was provided by the supplier of the machine. The calibration was repeated before each experiment to make sure that the data generated remains reproducible. Next, the OliverPharr model [37] was used to measure the hardness and Young's modulus data of the alumina samples from the experimentally measured load-depth $(P-h)$ data plots. No particular bias was associated with the location selection for the positions of the nanoindentation arrays. Thus, at least 100 individual measurements of hardness values were used for each reported average data. In the present experiments, peak load of $1 \mathrm{~N}$ was used. Further, both the loading and the unloading times were varied from $10^{0}$ to $10^{3}$ seconds to obtain the variation of loading rates in the range of $10^{-3}$ to $10^{0} \mathrm{~N} \cdot \mathrm{s}^{-1}$. Thus, the loading rate was calculated by dividing the peak load by the time to reach the peak load. For instance, a loading time of 1 second to reach a peak load of $1 \mathrm{~N}$ gives the loading rate of $10^{0} \mathrm{~N} \cdot \mathrm{s}^{-1}$. The error bars represent \pm 1 standard deviation of the data for all experimental data reported in this work. Field emission scanning electron microscope (FE-SEM, Supra VP35, Carl Zeiss, Germany) as mentioned earlier was also used to observe the microstructure and the indents in the present alumina samples.

\section{Results and Discussions}

FE-SEM photomicrograph (Figure 1) reveals the surface microstructure of the alumina having a relative density of $95 \%$ and grain size of $20 \mu \mathrm{m}$. The indentation experiments were conducted on this alumina sample at thirteen different loading rates in the range of $10^{-3}-10^{0} \mathrm{~N} \cdot \mathrm{s}^{-1}$ at a peak load of $1 \mathrm{~N}$. The loading part of the load-depth $(P-h)$ plots at thirteen different loading rates corresponding to $P_{\max }=$ $1 \mathrm{~N}$ is shown in Figure 2(a). Exploded views of 4 selected typical load versus depth plots from Figure 2(a) are shown 

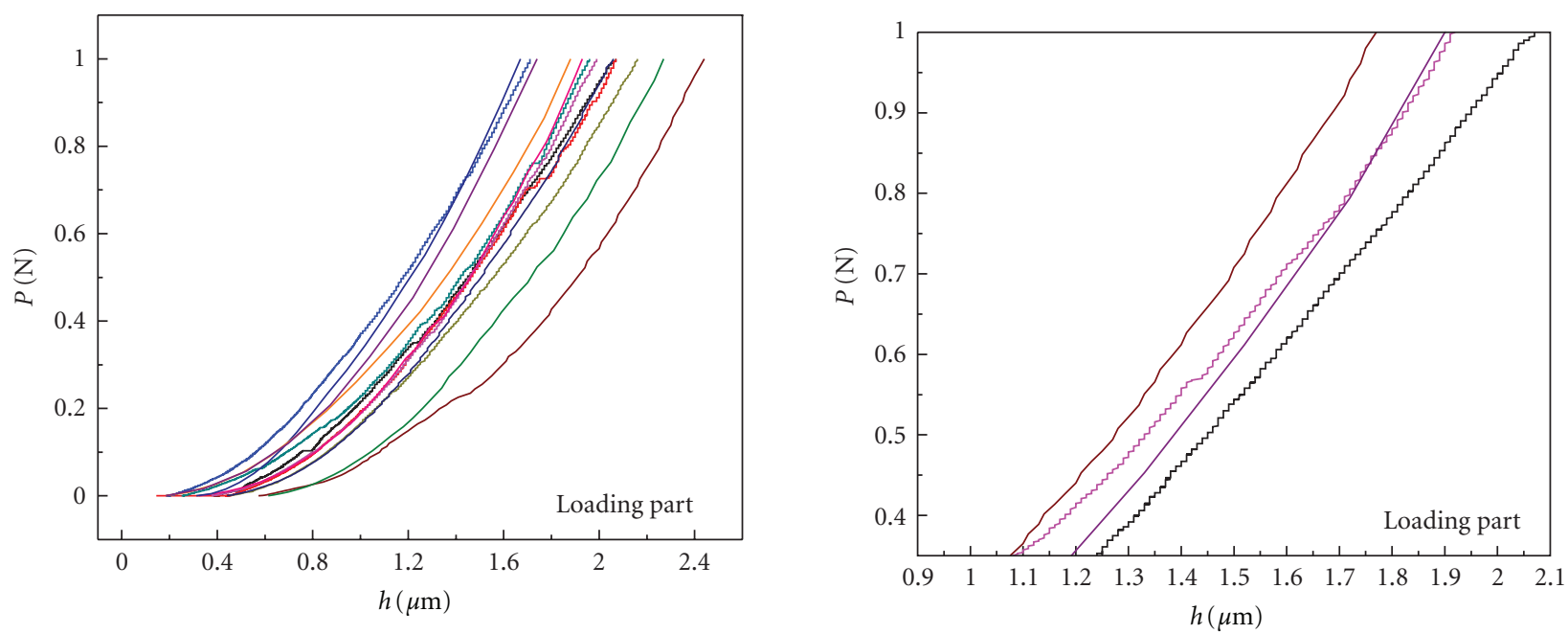

$\begin{array}{lll}-10^{-3} \mathrm{~N} \cdot \mathrm{s}^{-1} & 2 \times 10^{-2} \mathrm{~N} \cdot \mathrm{s}^{-1}-5 \times 10^{-1} \mathrm{~N} \cdot \mathrm{s}^{-1} \\ -1.5 \times 10^{-3} \mathrm{~N} \cdot \mathrm{s}^{-1} & -5 \times 10^{-2} \mathrm{~N} \cdot \mathrm{s}^{-1}-6.67 \times 10^{-1} \mathrm{~N} \cdot \mathrm{s}^{-1} \\ -2 \times 10^{-3} \mathrm{~N} \cdot \mathrm{s}^{-1} & -10^{-1} \mathrm{~N} \cdot \mathrm{s}^{-1}-10^{0} \mathrm{~N} \cdot \mathrm{s}^{-1} \\ -2.5 \times 10^{-3} \mathrm{~N} \cdot \mathrm{s}^{-1} & -2 \times 10^{-1} \mathrm{~N} \cdot \mathrm{s}^{-1} & \\ -10^{-2} \mathrm{~N} \cdot \mathrm{s}^{-1} & -2.5 \times 10^{-1} \mathrm{~N} \cdot \mathrm{s}^{-1} & \end{array}$

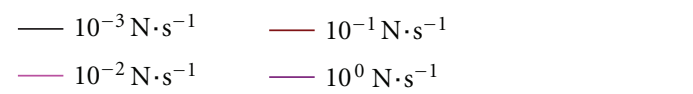

(a)
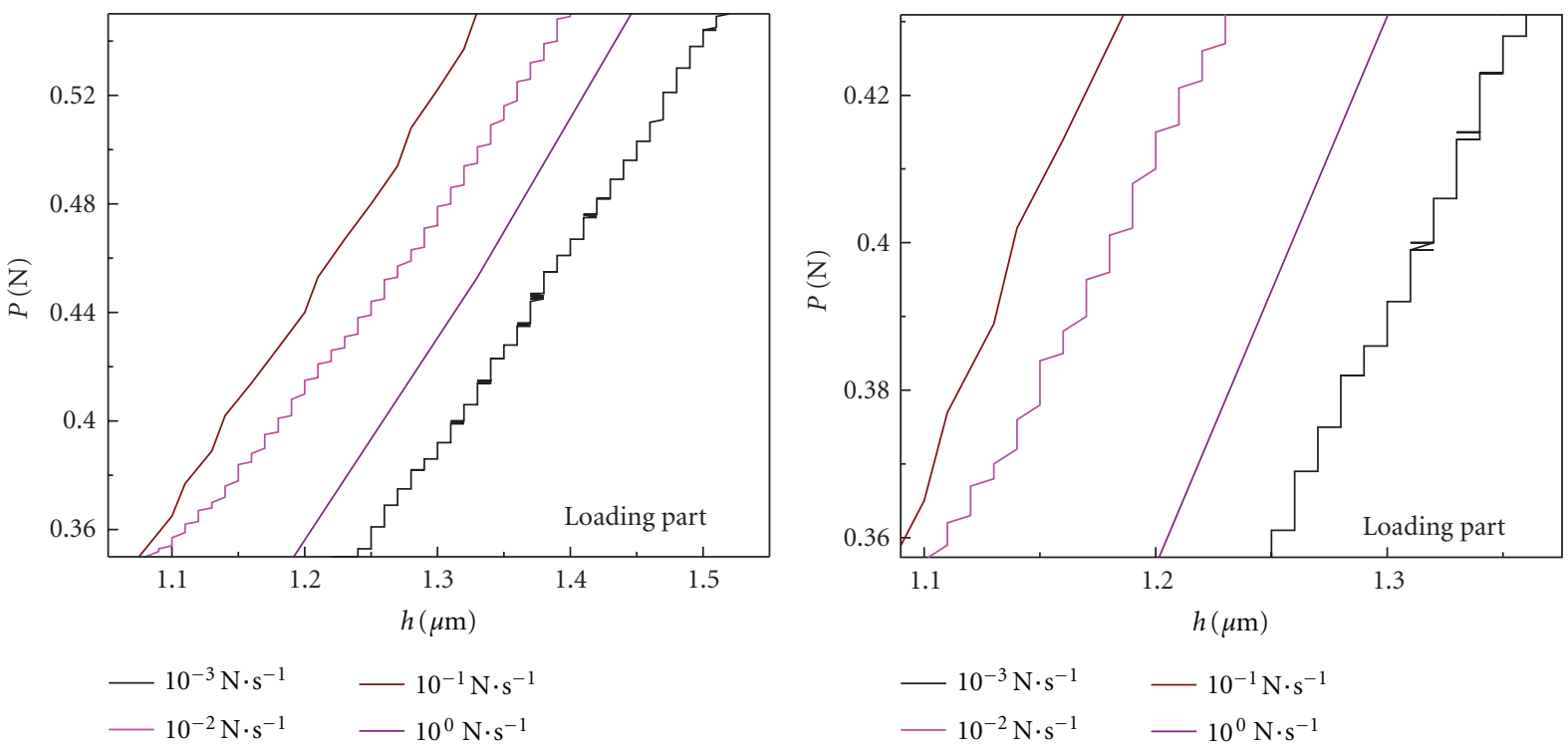

(c)

(d)

Figure 2: (a) Loading part of thirteen load-depth $(P-h)$ plots at different loading rates at an ultralow peak load of $1 \mathrm{~N}$, (b) exploded view of Figure 2(a) showing the presence of multiple micro-pop-in and micro-pop-out events at typical 4 selected loading rates $\left(10^{-3}, 10^{-2}, 10^{-1}\right.$, $10^{0} \mathrm{~N} \cdot \mathrm{s}^{-1}$ ), (c) exploded view of Figure 2(b) showing the variation of serrations with the loading rates, and (d) exploded view of Figure 2(c) showing clearly the occurrences of more number of serrations at lower loading rates and lesser number of serrations at higher loading rates.

in gradual exaggerations in the subsequent Figures 2(b)$2(\mathrm{~d})$. The $P$ - $h$ data plots revealed the presence of large number of serrations in the load-depth plots, Figure 2(b). These serrations were found to vary with the loading rates, Figures 2(b)-2(d). At lower loading rates, a large number of serrations occurred, while at higher loading rates, a much lesser number of serrations occurred, Figures 2(c) and 2(d).
Similar phenomenon was observed during the unloading part of the load-depth plots, Figures 3(a), 3(b), 3(c), and $3(d)$.

The serrations implied the occurrences of nanoscale localized plastic deformation signatures expressed in terms of micro-pop-in and micro-pop-out events in the loading and unloading parts. Similar observations were also reported for 

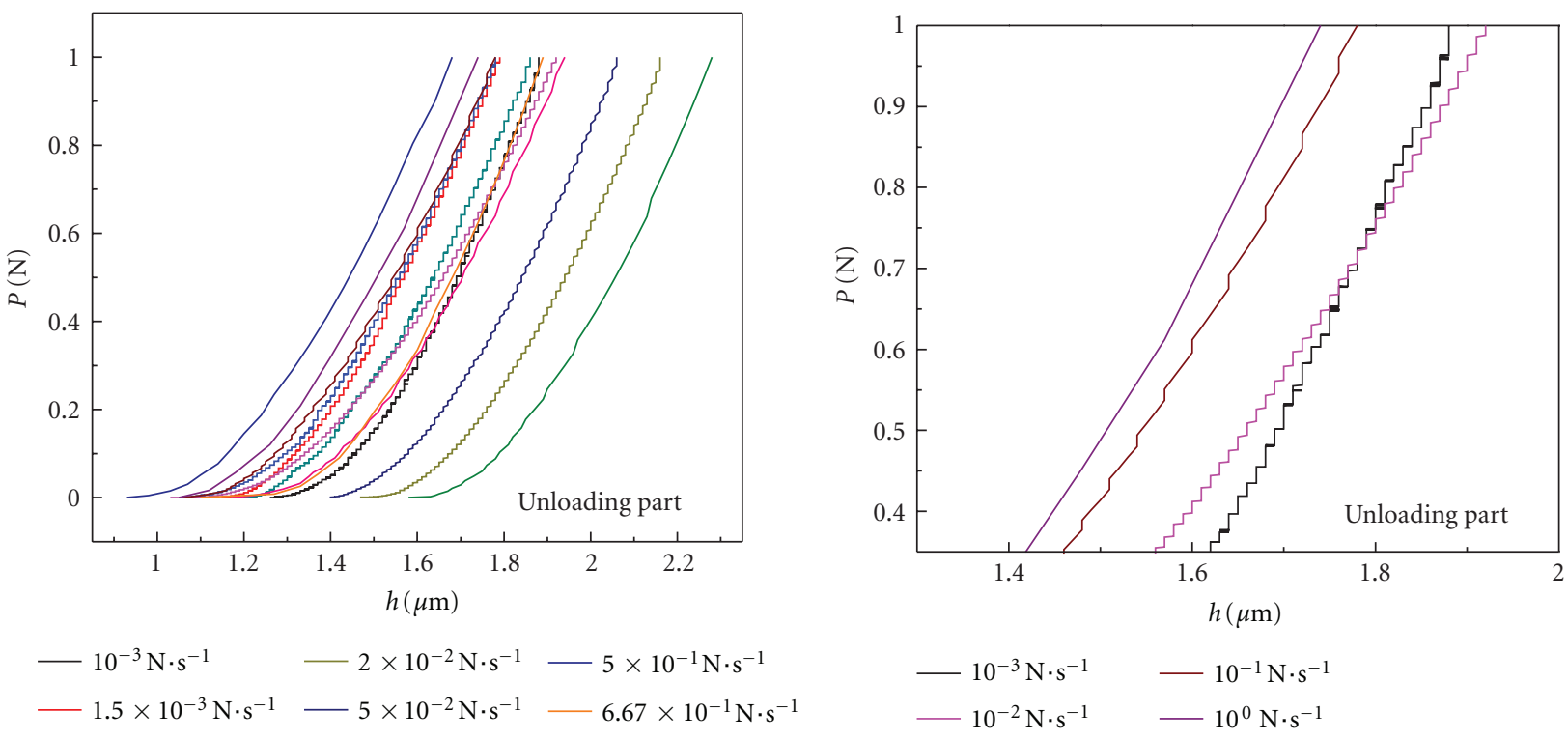

$\begin{array}{lll}-10^{-3} \mathrm{~N} \cdot \mathrm{s}^{-1} & -2 \times 10^{-2} \mathrm{~N} \cdot \mathrm{s}^{-1}-5 \times 10^{-1} \mathrm{~N} \cdot \mathrm{s}^{-1} \\ -1.5 \times 10^{-3} \mathrm{~N} \cdot \mathrm{s}^{-1} & -5 \times 10^{-2} \mathrm{~N} \cdot \mathrm{s}^{-1}-6.67 \times 10^{-1} \mathrm{~N} \cdot \mathrm{s}^{-1} \\ -2 \times 10^{-3} \mathrm{~N} \cdot \mathrm{s}^{-1} & -10^{-1} \mathrm{~N} \cdot \mathrm{s}^{-1}-10^{0} \mathrm{~N} \cdot \mathrm{s}^{-1} \\ -2.5 \times 10^{-3} \mathrm{~N} \cdot \mathrm{s}^{-1} & -2 \times 10^{-1} \mathrm{~N} \cdot \mathrm{s}^{-1} & \\ -10^{-2} \mathrm{~N} \cdot \mathrm{s}^{-1} & -2.5 \times 10^{-1} \mathrm{~N} \cdot \mathrm{s}^{-1}\end{array}$

(a)

(b)

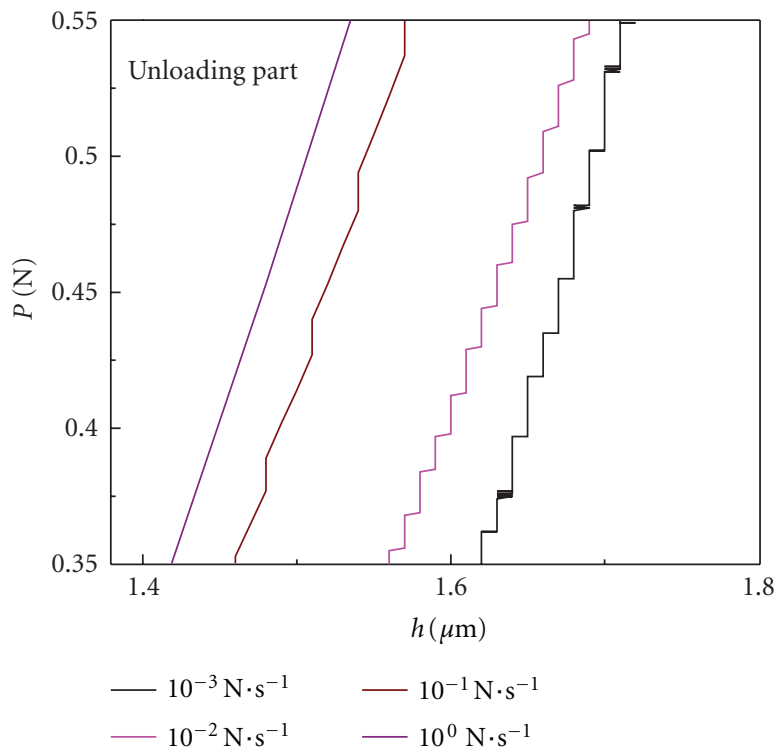

(c)

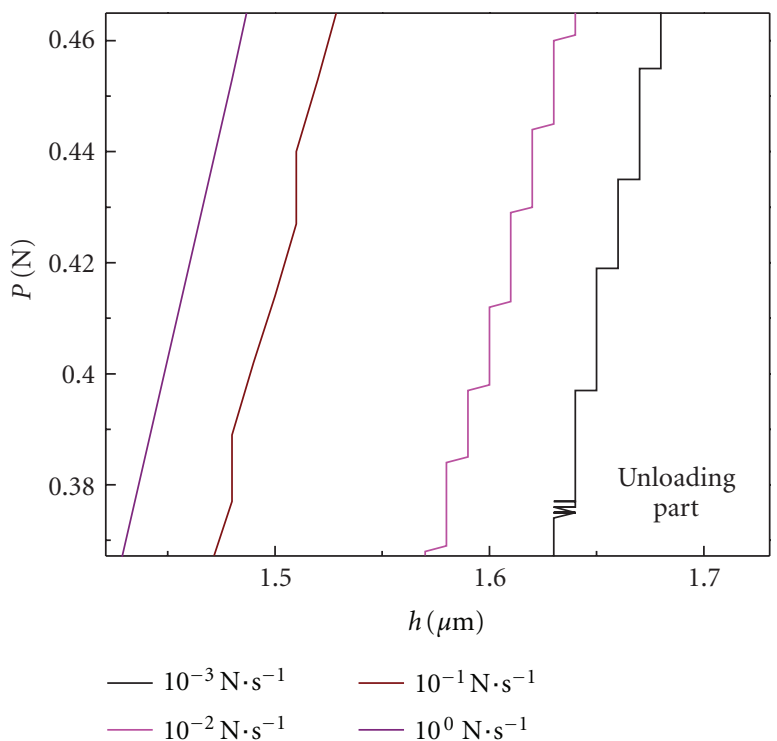

(d)

FIGURE 3: (a) Unloading part of thirteen load-depth $(P-h)$ plots at different loading rates at an ultralow peak load of $1 \mathrm{~N}$, (b) exploded view of Figure 3(a) showing the presence of multiple micro-pop-in and micro-pop-out events at typical 4 selected unloading rates $\left(10^{-3}, 10^{-2}\right.$, $\left.10^{-1}, 10^{0} \mathrm{~N} \cdot \mathrm{s}^{-1}\right)$, (c) exploded view of Figure 3(b) showing the variation of serrations with the unloading rates, and (d) exploded view of Figure 3(c) showing clearly the occurrences of more number of serrations at lower unloading rates and lesser number of serrations at higher unloading rates.

glass [21-24], polycrystalline alumina [25, 26, 43, 44], bulk metallic glasses [27-29], sapphire [30], GaN [31], and $\mathrm{ZnO}$ [32].

The load at which the nanoscale plasticity event had initiated is referred to as the critical load $\left(P_{c}\right)$. The high resolution FE-SEM photomicrograph (Figures 4(a) and 4(b)) showed shear-induced localized microcracking in the vicinity of the indent and microshear band formation inside the indentation cavity. The genesis of such nanoscale plasticity events has been correlated $[35,36]$ to shear burst 


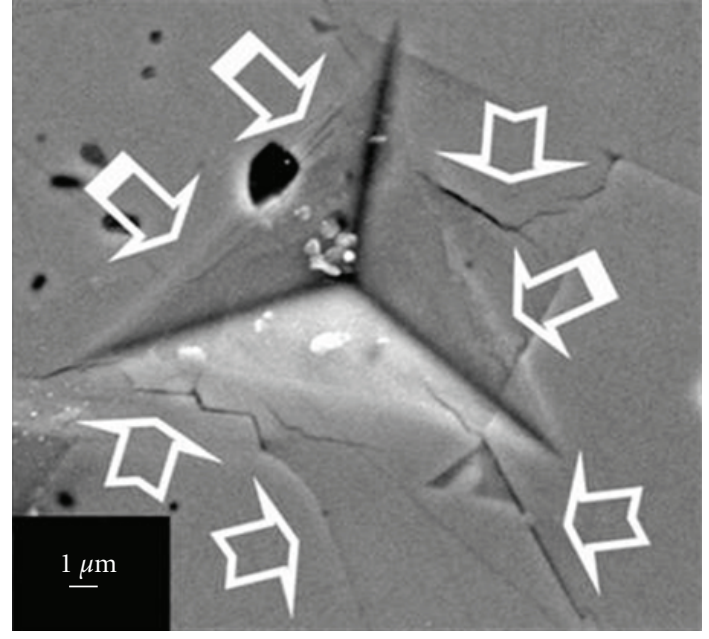

(a)

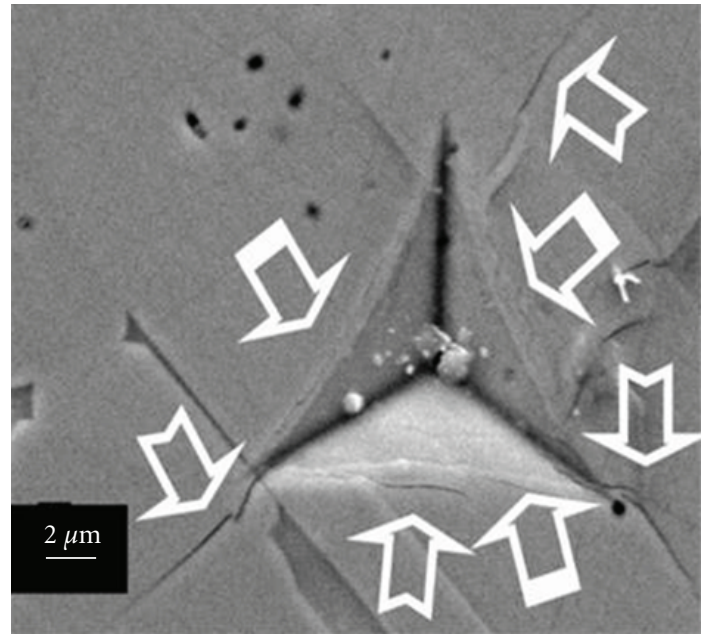

(b)

FIGURE 4: FE-SEM photomicrographs of shear-induced deformation band formation and microcracking (marked by hollow white arrows) at the indentation cavities of alumina at typical illustrative lower loading rates of (a) $2 \times 10^{-3}$ and (b) $10^{0} \mathrm{~N} \cdot \mathrm{s}^{-1}$.

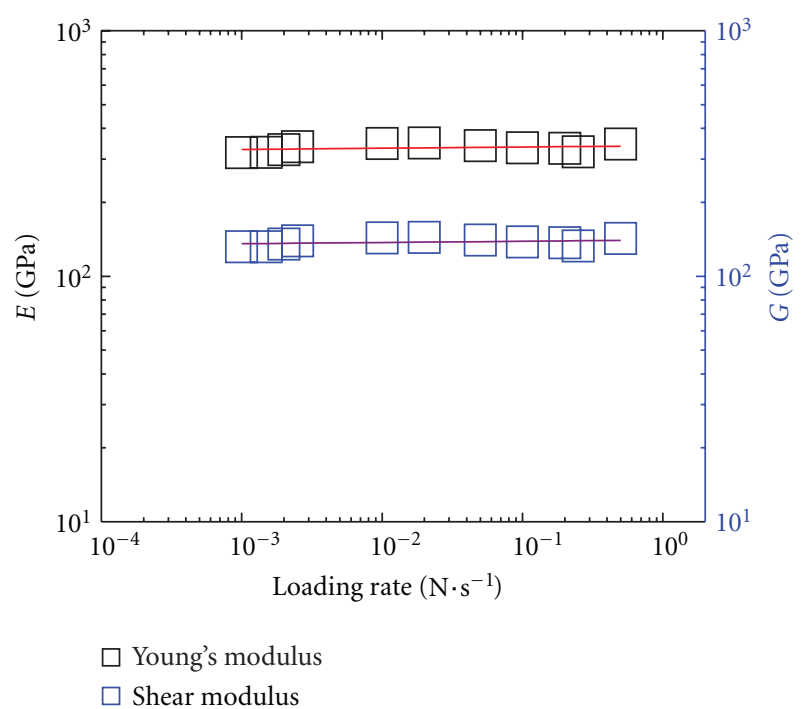

FIGURE 5: Variations of Young's modulus as well as shear modulus of the alumina sample with the loading rates. The solid lines indicate the power law fits of the corresponding plots.

and shear localization which initiate at a critical load $\left(P_{c}\right)$ as mentioned above.

However, microcrack formation requires a low value of the critical resolved shear stress $\left(\tau_{\mathrm{CRSS}}\right)$. Based on the measured Young's modulus for the present alumina $(E \sim$ $344.3 \mathrm{GPa}$ for $1 \mathrm{~N}$ ) [44], the values of shear modulus $G$ were estimated from $E /\left[2\left(1+v_{s}\right)\right]$ assuming $v_{s}$ as 0.21 [37]. The shear modulus $(G)$ data were not sensitive to the variations in loading rate $(\dot{P})$ as expected, Figure 5. Now, following the method suggested in [46] and using the present experimental data, the corresponding critical resolved shear stress $\left(\tau_{\mathrm{CRSS}}\right)$ values were evaluated assuming the magnitude of the Burger's vector $(\beta)$ as $\sim 0.5 \mathrm{~nm}[46]$.

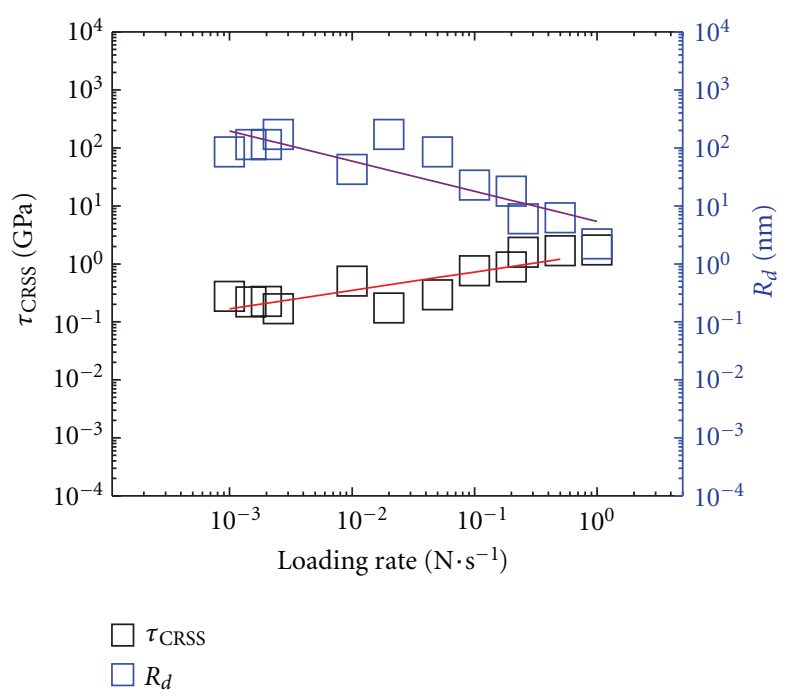

FIGURE 6: Variations of critical resolved shear stress ( $\left.\tau_{\text {CRSS }}\right)$ and the dislocation loop radii $\left(R_{d}\right)$ with the loading rates. The solid lines indicate corresponding power law fits.

It is interesting to note that the critical resolved shear stress $\left(\tau_{\text {CRSS }}\right)$ showed a power law dependence on the loading rates as shown in Figure 6 . The values of the estimated ( $\left.\tau_{\text {CRSS }}\right)$ were found to be very low $(0.6-1.85 \mathrm{GPa}$ for $1 \mathrm{~N})$. Thus, from the aforesaid values, the average critical resolved shear stress $\left(\overline{\tau_{\mathrm{CRSS}}}\right)$ value was estimated as $\sim 1.23 \mathrm{GPa}$ for the applied load of $1 \mathrm{~N}$. This value $(\sim 1.23 \mathrm{GPa}$ for $1 \mathrm{~N})$ for the present coarse grain alumina was lower than those, for example, $\sim 2-3 \mathrm{GPa}$ and $\sim 2.18 \mathrm{GPa}$, reported, respectively, for single crystal sapphire [46] and nanograined $\alpha$-alumina [35]. Furthermore, $\left(\overline{\tau_{\mathrm{CRSS}}}\right)$ was $\sim G / 116$ which compared favourably with $\left(\overline{\tau_{\text {CRSS }}}\right) \sim G / 100$ reported for sapphire [46]. Such a small magnitude of $\left(\overline{\tau_{\text {CRSS }}}\right)$ suggests a high possibility 
of localized microcracking around the indents, because of the high stresses generated at the small contact region, particularly at the vertices of the indents due to the steep change in slopes of the supporting contact area. The high resolution FE-SEM photomicrographs (Figures 4(a) and 4(b)) indeed provide necessary evidence in support of such a picture.

Now we would like to discuss the possibility of dislocation nucleation that might have had led to the initiation of nanoscale plasticity events in the coarse grained alumina. Thus, following the method suggested by Gouldstone et al. [47], the possible range of dislocation loop radius $\left(R_{d}\right)$ data was estimated as a function of the loading rates, considering the typical magnitude of Burger's vector $(\beta) \sim 0.5 \mathrm{~nm}[46]$ as mentioned before.

Assuming that the typical maximum effective thickness within which the dislocation loops generated underneath the indenter will be typically $\sim$ one-tenth of the grain size, the range of dislocation loop radius $\left(R_{d}\right)$ data was estimated as $\sim 85-2.2 \mathrm{~nm}$ corresponding to the range (e.g., $10^{-3}-$ $10^{0} \mathrm{~N} \cdot \mathrm{s}^{-1}$ ) of loading rates. The prediction of the $R_{d}$ data required the use of critical load $\left(P_{c}\right)$ and critical depth $\left(h_{c}\right)$ data determined from the experimentally measured load depth plots, Figures 2(a)-2(d) obtained during the loading cycles.

It may be noted that $R_{d}$ was much greater than $\beta[35,36]$. Furthermore, the value of $R_{d} \sim 2.2 \mathrm{~nm}$ compared favourably with the value of $R_{d} \sim 3.2 \mathrm{~nm}$ reported for nanograined $\alpha$-alumina [35]. The variation of $R_{d}$ exhibited a power law dependence on the loading rate with a negative exponent, Figure 6.

At lower loading rates the indenter spent longer time in contact with the alumina microstructure. Hence it was expected to face more microstructural obstruction during penetration process. However, at higher loading rates, it spent comparatively much lower amount of time, for example, $1 \mathrm{sec}$, in contact with the alumina microstructure. Therefore, it was highly likely that the amount of microstructural obstruction faced by the penetrating indenter would be much lesser in this case. Thus, the data presented in Figure 6 would suggest that, at higher loading rates, the indenter penetrated for relatively lesser amounts of time and hence it possibly faced lesser obstructions.

As the amount of obstruction faced was less, the radius of the dislocation loop was very small, for example, $\sim 2.2 \mathrm{~nm}$ at higher loading rate. Then it would be logical to argue that the total number of dislocations nucleated per unit volume of the coarse grain alumina at higher loading rates would be much more than those nucleated at lower loading rates, where the dislocation loop radii were predicted to be relatively larger, for example, $\sim 85 \mathrm{~nm}$.

The more the number of such nanoscale plasticity events would occur, the more would be the amount of strain in the microstructure. Therefore, it was not surprising that the hardness of the present alumina increased by about $6.64 \%$ (Figure 7) as the loading rate was increased from $10^{-3}$ to $10^{0}$ $\mathrm{N} \cdot \mathrm{s}^{-1}$.

In this context, the maximum shear stress $\tau_{\max }$ developed underneath the indenter was calculated [33, 34] and the data are incorporated in the same plot (Figure 7) as a

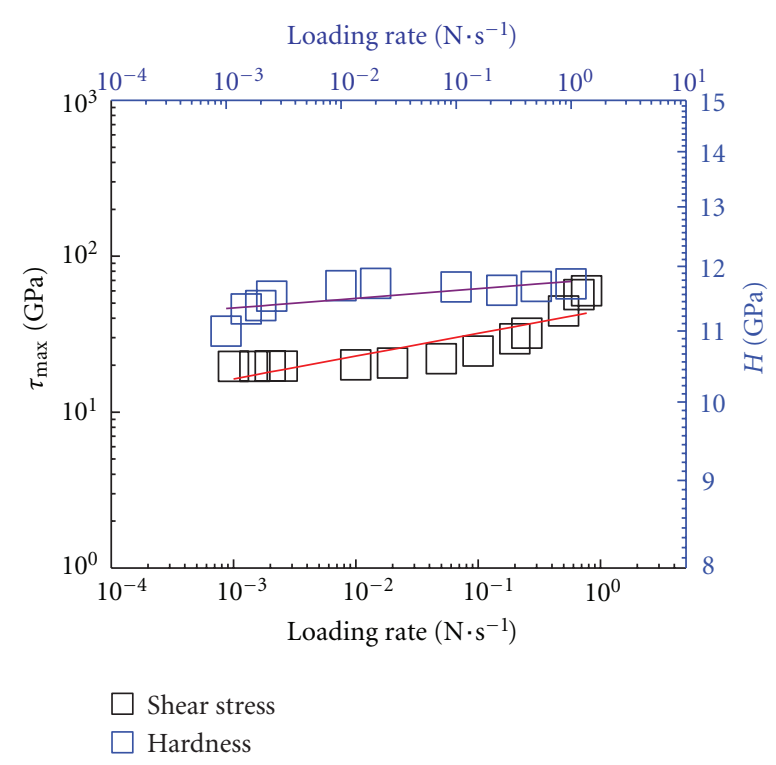

FIGURE 7: Variations of the maximum shear stress generated underneath the indenter $\left(\tau_{\max }\right)$ and the hardness $(H)$ of the present alumina ceramic with the loading rates. The solid lines indicate the corresponding power law fits.

function of loading rate. It was interesting to note that the maximum shear stress showed an empirical power law dependence with a positive exponent on the loading rate. Furthermore, it might be mentioned that the estimated average of the maximum shear stress $\left(\overline{\tau_{\max }} \sim 30 \pm 14.5 \mathrm{GPa}\right)$ active at depth of about 0.35 times the static contact radius (a) was much greater than the theoretical shear strength (e.g., $\sim 3 \mathrm{GPa}$ ) of alumina [10] and hence shear-induced deformation and/or fracture was expected (Figures 4(a) and $4(\mathrm{~b}))$. Other researchers also reported $\left(\overline{\tau_{\max }} \sim 28 \mathrm{GPa}\right)$ for polycrystalline $\alpha$-alumina $[35,36]$ located at the depths of 0.41 to 0.5 times the static contact radius $(a)$.

Furthermore, the similar nature of power law dependencies of the maximum shear stress $\left(\tau_{\max }\right)$ developed underneath the indenter and hardness on the loading rate with positive exponents suggested that there was a relationship between the increase in hardness and $\tau_{\max }$. This conjecture is indeed strongly supported by the data presented in Figure 8 which demonstrate that the rate of change in hardness of the alumina with loading rate was linearly dependent on the rate of change of the maximum shear stress with loading rate.

In other words, the higher magnitude of maximum shear stress at higher loading rate could have had easily played a pivotal role in nucleating more number of nanoscale plasticity events (because the dislocation loop radii were low) and thereby more localized strain accumulation in the microstructure of the alumina. The apparent small increase of about $6.64 \%$ in hardness may be the result of such a microstructural localized strain accumulation process. The characteristic lower magnitude of the critical resolved shear stress of course had aided some release of stress around the indent cavity through formation of highly localized microcracks. 


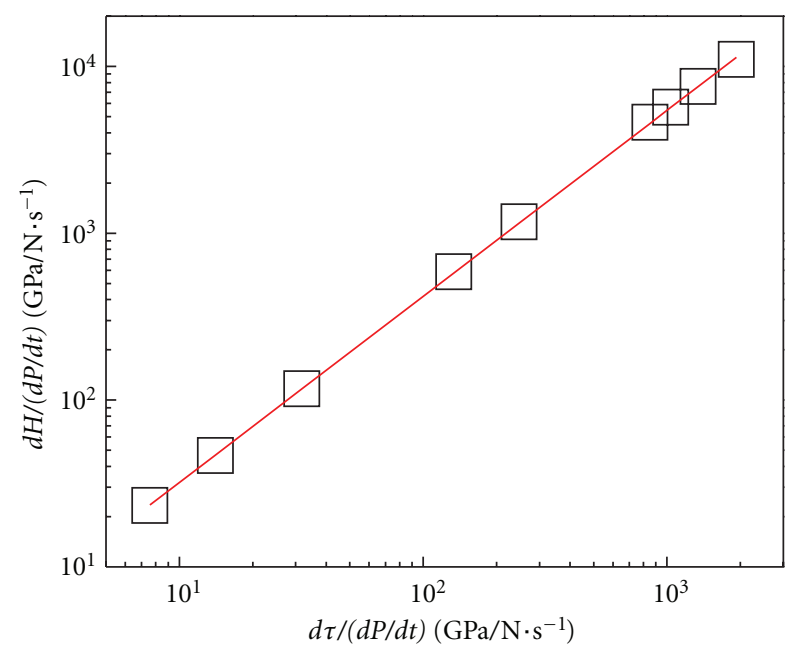

FIGURE 8: Variations of the rate of change of hardness of the present alumina ceramic with loading rates as a function of the rate of change of the maximum shear stress with the loading rates. The solid line indicates the corresponding power law fit.
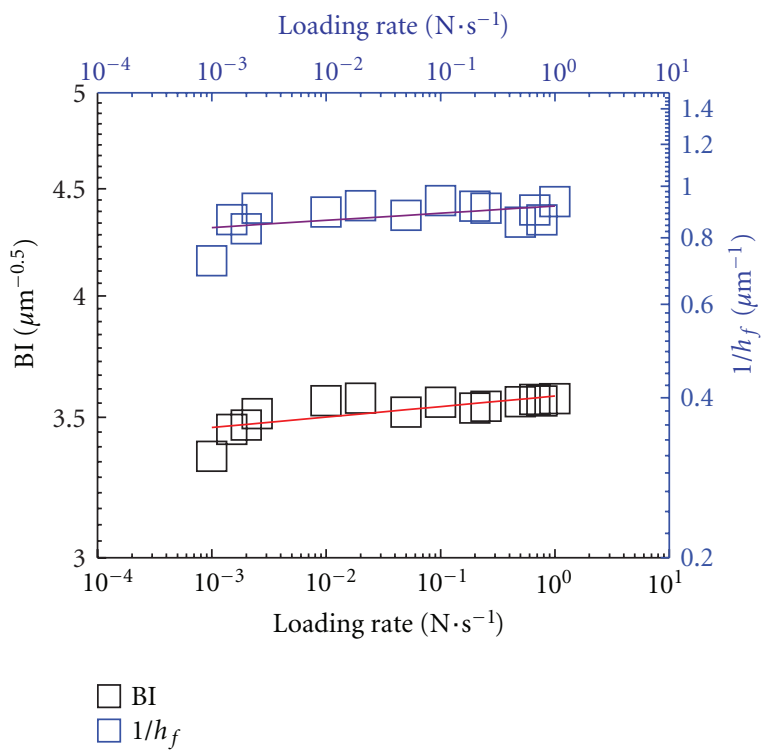

FIgURE 9: Variations of the brittleness index (BI) and the contact deformation resistance parameter $\left(1 / h_{f}\right)$ of the present dense, coarse grained alumina ceramic as a function of the loading rates. The solid lines indicate the corresponding power law fits.

Such a picture is further supported by the fact that both the brittleness index (BI) calculated [50] and the characteristic contact deformation resistance parameter defined for the first time in the present work as $1 / h_{f}$ increased with the loading rate, following empirical power law dependencies with positive exponents, Figure 9. In this context it should be mentioned that the fracture toughness for the present alumina sample was measured by the conventional indentation fracture technique [51] to be $\sim 3.28 \pm 0.65 \mathrm{MPa} \cdot \mathrm{m}^{0.5}$. This data was used for calculating the brittleness index following [50]. Thus, the data presented in Figure 9 implied that the higher the contact deformation resistance of the present alumina, the more prone it became to contact-induced fracture as expected for characteristically brittle solids.

Although large number of nanoscale plasticity events could have occurred at higher loading rates as discussed above, it should be kept in mind that here the contact time between the indenter and the alumina sample was really very small. As a result, at higher loading rates, only the overall average elastoplastic and plastic deformation processes might have had come into play. In such a scenario, the simultaneous operation of multiple nanoscale plasticity events, for example, large number of dislocation nucleations due to high shear stress active at the vicinity of the tip of the indenter, could have had forced a homogenization of the plastic deformation response of the present alumina ceramics. This picture is supported by the fact that, on a comparative scale, a much lower number of serrations could be observed in the experimentally obtained load versus depth of penetration plots at higher loading rates (Figure 2).

On the other hand, at lower loading rates, there was comparatively longer interaction time, for example, up to $1000 \mathrm{sec}$, available during the indentation process. As a result, the action of the first, the immediate next one, and all such consequent nanoscale plasticity events might have had come into play nearly sequentially one after another. It is proposed that due to this sequential discrete fashion action of the multiple nanoscale plasticity events the multiple serrations appeared one after another in the $P$ - $h$ plots (Figure 2) recorded for the present alumina ceramic.

\section{Conclusions}

We presented an experimental observation of a high density (95\% of theoretical) coarse grain $(\sim 20 \mu \mathrm{m})$ alumina, undergoing indentation at an ultralow peak load of $1 \mathrm{~N}$. The hardness of the material against the initiation of nanoscale plasticity events can enhance with the loading rates following a power law dependence with a positive exponent. This enhancement is explained by the increase in maximum shear stress developed under the indenter with the loading rates. The apparent increase in hardness of the alumina was well supported by the decrease in the dislocation loop radius with the loading rates, creating, thereby, more number of dislocation nucleations at higher loading rates. Also, we found that the brittleness index of the coarse grain alumina can register an apparent increase with the loading rates and, hence, we can define a new parameter called contact deformation resistance $\left(1 / h_{f}\right)$ that also increases with the loading rates.

\section{Acknowledgments}

The authors are grateful to the Director of CSIR-Central Glass and Ceramic Research Institute (CGCRI), Kolkata, for his kind permission to publish this paper. In addition, the authors appreciate the infrastructural supports received from all colleagues and particularly those received from the colleagues of the Mechanical Property Evaluation Section, 
NOCCD. Finally, the authors gratefully acknowledge the financial supports received from CSIR (Project no. NWP 0027, NWP 0029).

\section{References}

[1] A. Z. A. Azhar, L. C. Choong, H. Mohamad, M. M. Ratnam, and Z. A. Ahmad, "Effects of $\mathrm{Cr}_{2} \mathrm{O}_{3}$ addition on the mechanical properties, microstructure and wear performance of zirconia-toughened-alumina (ZTA) cutting inserts," Journal of Alloys and Compounds, vol. 513, no. 5, pp. 91-96, 2012.

[2] S. Affatato, P. Taddei, S. Carmignato, E. Modena, and A. Toni, "Severe damage of alumina-on-alumina hip implants: wear assessments at a microscopic level," Journal of the European Ceramic Society, vol. 32, no. 14, pp. 3647-3657, 2012.

[3] S. T. Aruna, N. Balaji, J. Shedthi, and V. K. William Grips, "Effect of critical plasma spray parameters on the microstructure, microhardness and wear and corrosion resistance of plasma sprayed alumina coatings," Surface \& Coatings Technology, vol. 208, pp. 92-100, 2012.

[4] C. T. Wang, C. W. Lin, C. L. Hsia, B. W. Chang, and M. F. Luo, "Under-surface observation of thin-film alumina on $\mathrm{NiAl}(100)$ with scanning tunneling microscopy," Thin Solid Films, vol. 520, no. 11, pp. 3952-3959, 2012.

[5] C. W. Ong, C. W. Boey, R. S. Hixson, and J. O. Sinibaldi, "Advanced layered personnel armor," International Journal of Impact Engineering, vol. 38, no. 5, pp. 369-383, 2011.

[6] J. Olofsson, U. Bexell, and S. Jacobson, "Tribofilm formation of lightly loaded self mated alumina contacts," Wear, vol. 289, pp. 39-45, 2012.

[7] F. Inam, T. Peijs, and M. J. Reece, "The production of advanced fine-grained alumina by carbon nanotube addition," Journal of the European Ceramic Society, vol. 31, no. 15, pp. 2853-2859, 2011.

[8] A. N. Rascon, A. A. Elguezabal, E. Orrantia, and M. H. B. Bernal, "Compressive strength, hardness and fracture toughness of $\mathrm{Al}_{2} \mathrm{O}_{3}$ whiskers reinforced ZTA and ATZ nanocomposites: weibull analysis," International Journal of Refractory Metals and Hard Materials, vol. 29, no. 3, pp. 333-340, 2011.

[9] L. C. Urkovic, I. Kumic, and K. Grilec, "Solid particle erosion behaviour of high purity alumina ceramics," Ceramics International, vol. 37, no. 1, pp. 29-35, 2011.

[10] G. R. Anstis, P. Chantikul, B. R. Lawn, and D. B. Marshall, "A critical evaluation of indentation techniques for measuring fracture toughness: I, direct crack measurements," Journal of the American Ceramic Society, vol. 64, no. 9, pp. 533-538, 1981.

[11] A. Krell and P. Blank, "Grain size dependence of hardness in dense submicrometer alumina," Journal of the American Ceramic Society, vol. 78, no. 4, pp. 1118-1120, 1995.

[12] A. Franco, S. G. Roberts, and P. D. Warren, "Fracture toughness, surface flaw sizes and flaw densities in $\mathrm{Al}_{2} \mathrm{O}_{3}$," Acta Materialia, vol. 45, no. 3, pp. 1009-1015, 1997.

[13] A. Krell and S. Schädlich, "Nanoindentation hardness of submicrometer alumina ceramics," Materials Science and Engineering A, vol. 307, no. 1-2, pp. 172-181, 2001.

[14] A. Krell, P. Blank, H. Ma, T. Hutzler, and M. Nebelung, "Processing of high-density submicrometer $\mathrm{Al}_{2} \mathrm{O}_{3}$ for new applications," Journal of the American Ceramic Society, vol. 86, no. 4, pp. 546-553, 2003.

[15] N. Dwivedi and S. Kumar, "Nanoindentation testing on copper/diamond-like carbon bi-layer films," Current Applied Physics, vol. 12, no. 1, pp. 247-253, 2011.
[16] D. Drechsler, A. Karbach, and H. Fuchs, "Nanoindentation on polycarbonate/polymethyl methacrylate blends," Applied Physics A, vol. 66, supplement 1, pp. S825-S829, 1998.

[17] R. Longtin, C. Fauteux, E. Coronel, U. Wiklund, J. Pegna, and M. Boman, "Nanoindentation of carbon microfibers deposited by laser-assisted chemical vapor deposition," Applied Physics A, vol. 79, no. 3, pp. 573-577, 2004.

[18] W. Gindl, H. S. Gupta, T. Schöberl, H. C. Lichtenegger, and P. Fratzl, "Mechanical properties of spruce wood cell walls by nanoindentation," Applied Physics A, vol. 79, no. 8, pp. 20692073, 2004.

[19] B. W. Choi, D. H. Seo, and J. I. Jang, "A nanoindentation study on the micromechanical characteristics of API X100 pipeline steel," Metals and Materials International, vol. 15, no. 3, pp. 373-378, 2009.

[20] L. Boudoukha, F. Halitim, S. Paletto, and G. Fantozzi, "Mechanical properties of titanium implanted polycrystalline alumina and sapphire determined by nanoindentation," Ceramics International, vol. 24, no. 3, pp. 189-198, 1998.

[21] R. Chakraborty, A. Dey, and A. K. Mukhopadhyay, "Loading rate effect on nanohardness of soda-lime-silica glass," Metallurgical and Materials Transactions A, vol. 41, no. 5, pp. 13011312, 2010.

[22] A. Dey, R. Chakraborty, and A. K. Mukhopadhyay, "Nanoindentation of soda lime-silica glass: effect of loading rate," International Journal of Applied Glass Science, vol. 2, no. 2, pp. 144-155, 2011.

[23] A. Dey, R. Chakraborty, and A. K. Mukhopadhyay, "Enhancement in nanohardness of soda-lime-silica glass," Journal of Non-Crystalline Solids, vol. 357, no. 15, pp. 2934-2940, 2011.

[24] R. Chakraborty, A. Dey, and A. K. Mukhopadhyay, "Role of the energy of plastic deformation and the effect of loading rate on nanohardness of soda-lime-silica glass," Physics and Chemistry of Glasses: European Journal of Glass Science and Technology Part B, vol. 51, no. 6, pp. 293-303, 2010.

[25] M. Bhattacharya, R. Chakraborty, A. Dey, A. K. Mukhopadhyay, and S. K. Biswas, "Effect of loading rate on nanomechanical properties of alumina," in Proceedings of the Workshop on Mechanical Behaviour of Systems at Small Length Scales-3, p. 40, Trivandrum, India, September 2011.

[26] S. Bhuniya, R. Chakraborty, A. Dey et al., "Effect of loading rate on microhardness of alumina ceramics," in Proceedings of the High Pressure Science and Technology (AIRAPT 23), p. 188, BARC, Mumbai, India, September 2011.

[27] C. A. Schuh, T. G. Nieh, and Y. Kawamura, "Rate dependence of serrated flow during nanoindentation of a bulk metallic glass," Journal of Materials Research, vol. 17, no. 7, pp. 16511654, 2002.

[28] Y. I. Golovin, V. I. Ivolgin, V. A. Khonik, K. Kitagawa, and A. I. Tyurin, "Serrated plastic flow during nanoindentation of a bulk metallic glass," Scripta Materialia, vol. 45, no. 8, pp. 947952, 2001.

[29] C. A. Schuh and T. G. Nieh, "A nanoindentation study of serrated flow in bulk metallic glasses," Acta Materialia, vol. 51, no. 1, pp. 87-99, 2003.

[30] R. Nowak, T. Sekino, and K. Niihara, "Surface deformation of sapphire crystal," Philosophical Magazine A, vol. 74, no. 1, pp. 171-194, 1996.

[31] J. E. Bradby, S. O. Kucheyev, J. S. Williams et al., "Indentationinduced damage in GaN epilayers," Applied Physics Letters, vol. 80, no. 3, pp. 383-385, 2002.

[32] S. O. Kucheyev, J. E. Bradby, J. S. Williams, C. Jagadish, and M. V. Swain, "Mechanical deformation of single-crystal ZnO," Applied Physics Letters, vol. 80, no. 6, pp. 956-958, 2002. 
[33] C. E. Packard and C. A. Schuh, "Initiation of shear bands near a stress concentration in metallic glass," Acta Materialia, vol. 55, no. 16, pp. 5348-5358, 2007.

[34] H. Shang, T. Rouxel, M. Buckley, and C. Bernard, "Viscoelastic behavior of a soda-lime-silica glass in the 293-833 K range by micro-indentation," Journal of Materials Research, vol. 21, no. 3, pp. 632-638, 2006.

[35] W. G. Mao, Y. G. Shen, and C. Lu, "Deformation behavior and mechanical properties of polycrystalline and single crystal alumina during nanoindentation," Scripta Materialia, vol. 65, no. 2, pp. 127-130, 2011.

[36] W. G. Mao, Y. G. Shen, and C. Lu, "Nanoscale elastic-plastic deformation and stress distributions of the $\mathrm{C}$ plane of sapphire single crystal during nanoindentation," Journal of the European Ceramic Society, vol. 31, no. 10, pp. 1865-1871, 2011.

[37] W. C. Oliver and G. M. Pharr, "Measurement of hardness and elastic modulus by instrumented indentation: advances in understanding and refinements to methodology," Journal of Materials Research, vol. 19, no. 1, pp. 3-20, 2004.

[38] A. G. Evans and T. R. Wilshaw, "Dynamic solid particle damage in brittle materials: an appraisal," Journal of Materials Science, vol. 12, no. 1, pp. 97-116, 1977.

[39] M. M. Chaudhri, J. K. Wells, and A. Stephens, "Dynamic hardness, deformation and fracture of simple ionic crystals at very high rates of strain," Philosophical Magazine A, vol. 43, no. 3, pp. 643-664, 1981.

[40] D. B. Marshall, A. G. Evans, and Z. Nisenholz, "Measurement of dynamic hardness by controlled sharp-projectile impact," Journal of the American Ceramic Society, vol. 66, no. 8, pp. 580585, 1983.

[41] R. J. Anton and G. Subhash, "Dynamic Vickers indentation of brittle materials," Wear, vol. 239, no. 1, pp. 27-35, 2000.

[42] G. D. Quinn, P. J. Patel, and I. Lloyd, "Effect of loading rate upon conventional ceramic microindentation hardness," Journal of Research of the National Institute of Standards and Technology, vol. 107, no. 3, pp. 299-306, 2002.

[43] M. Bhattacharya, R. Chakraborty, A. Dey, A. K. Mandal, and A. K. Mukhopadhyay, "Improvement in nanoscale contact resistance of alumina," Applied Physics, vol. 107, no. 4, pp. 783788, 2012.

[44] M. Bhattacharya, R. Chakraborty, A. Dey, A. K. Mandal, and A. K. Mukhopadhyay, "New observations in micro-pop-in issuesin nanoindentation of coarse grain alumina," Ceramics International. In press.

[45] H. Bei, Y. F. Gao, S. Shim, E. P. George, and G. M. Pharr, "Strength differences arising from homogeneous versus heterogeneous dislocation nucleation," Physical Review B, vol. 77, no. 6, Article ID 060103, 4 pages, 2008.

[46] T. F. Page, W. C. Oliver, and C. J. McHargue, "The deformation-behavior of ceramic crystals subjected to very low load (nano)indentations," Journal of Materials Research, vol. 7, no. 2, pp. 450-473, 1992.

[47] A. Gouldstone, H. J. Koh, K. Y. Zeng, A. E. Giannakopoulos, and S. Suresh, "Discrete and continuous deformation during nanoindentation of thin films," Acta Materialia, vol. 48, no. 9, pp. 2277-2295, 2000.

[48] C. A. Schuh and A. C. Lund, "Application of nucleation theory to the rate dependence of incipient plasticity during nanoindentation," Journal of Materials Research, vol. 19, no. 7, pp. 2152-2158, 2004.

[49] T. Ebisu and S. Horibe, "Analysis of the indentation size effect in brittle materials from nanoindentation load-displacement curve," Journal of the European Ceramic Society, vol. 30, no. 12, pp. 2419-2426, 2010.
[50] B. R. Lawn and D. B. Marshall, "Residual stress effects in failure from flaws," Journal of the American Ceramic Society, vol. 62, no. 1-2, pp. 106-108, 1979.

[51] A. G. Evans, "Perspective on the development of hightoughness ceramics," Journal of the American Ceramic Society, vol. 73, no. 2, pp. 187-206, 1990. 

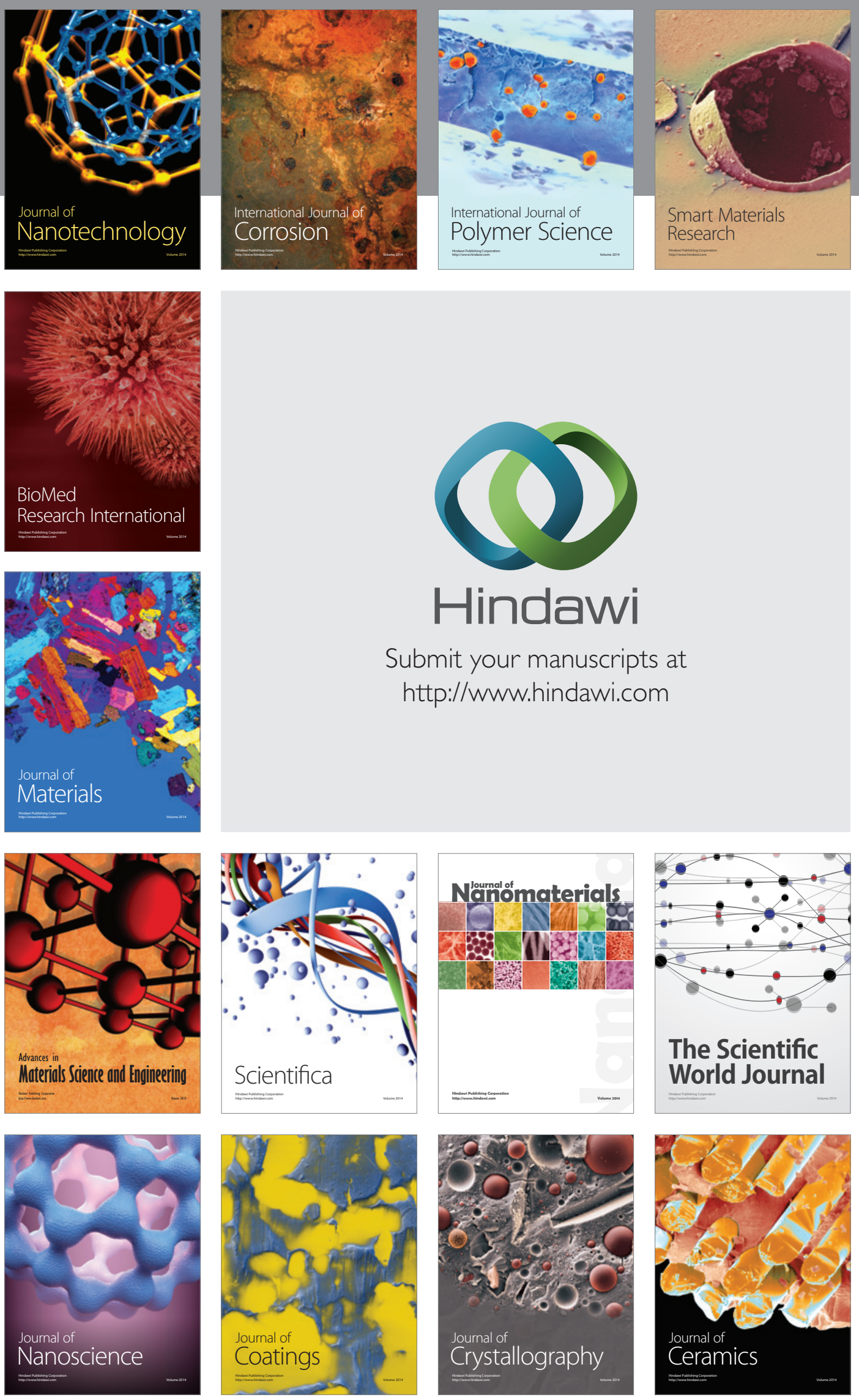

The Scientific World Journal

Submit your manuscripts at

http://www.hindawi.com

\section{World Journal}

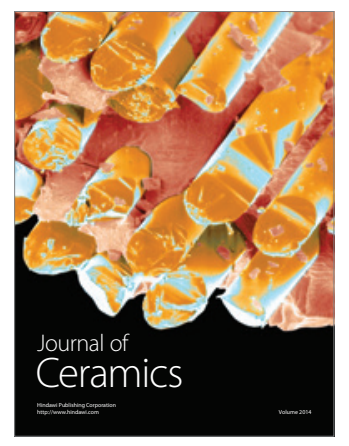

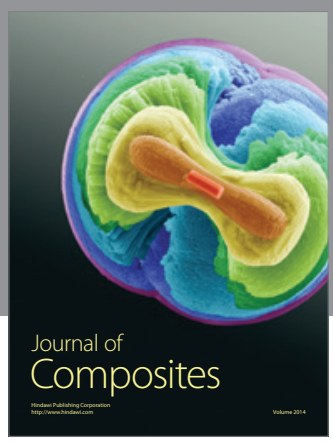
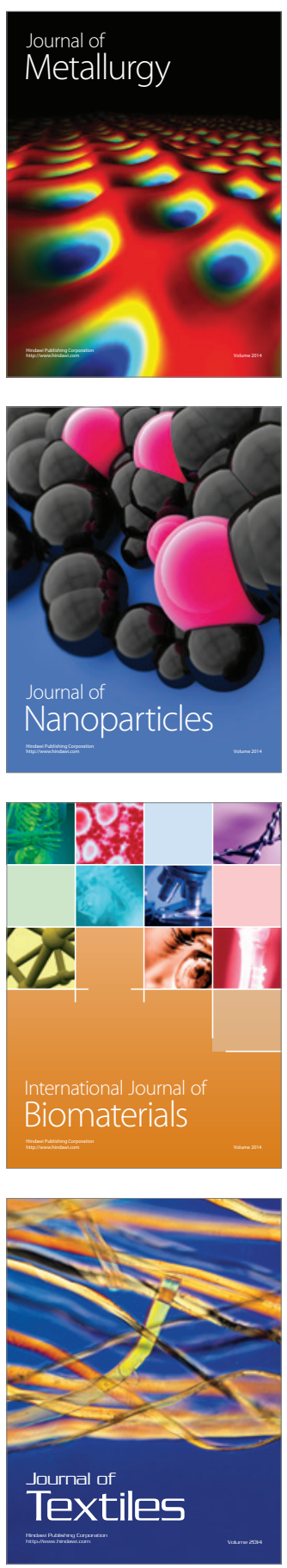